\title{
Perancangan Video Promosi Objek Wisata Ranudi Kabupaten Probolinggo Jawa Timur
}

\author{
Riyanti Suci Purwasi ${ }^{\mathbf{1}}$, Faldi Hendrawan ${ }^{2}$ Ahmad Zakiy Ramadhan ${ }^{3}$ \\ ${ }_{1,2,3}$ Desain Komunikasi Visual \\ ${ }^{1}$ riyantisuci@gmail.com, ${ }^{2}$ faldikobenasia@gmail.com
}

\begin{abstract}
ABSTRAK
Pesatnya kemajuan teknologi informatika (IT) memberikan kemudahan dalam mengakses dan menyajikan informasi dalam berbagai bentuk dan media, secara umumnya (buku, brosur, majalah, tabloid, dan poster), maupun dalam bentuk format elektronik atau digital (internet, film, cd-interaktif dan game). Dengan tersedianya banyak penyajian maka data hasil-hasil penelitian dapat disajikan dengan lebih menarik dan mudah digunakan maka data hasil-hasil digunakan, seperti mengandung unsur informasi Media ini berupa video promosi tentang Objek Wisata Ranu di Kabupaten Probolinggo-Jawa Timur. Video memberikan info tantang wisata Ranu di Kabupaten Probolinggo-Jawa Timur. Media promosi ini nantinya akan disajikan berupa video promosi dan informasi yang nantinya dapat memudahkan para wisatawan untuk mengetahui tentang WIsata Ranu di Kabupaten Probolinggo-Jawa Timur dan bertujuan untuk memikat daya tarik para wisatawan baik lokal maupun mancanegara untuk datang dan berpariwisata di Kabupaten Probolinggo. Format MPEG (MotionPicture Expert Group) dipilih karena memiliki beberapa kelebihan, diantaranya MPEG merupakan standart international untuk format digital audio \& video, biasanya digunakan untuk VCD \& DVD. Dalam membuat sebuah video sebagai media promosi yang menarik, media ini dibuat dengan beberapa elemen seperti konsep videografi, storyline, storyboard, dan audio. Software pendukung pada tahap pasca produksi adalah Adobe After Effect untuk membuat opening, Adobe Photoshop untuk mendesain informasi, dan Adobe Premiere Pro digunakan untuk proses editing video. Dari hasil responden, nilai presentase dari masyarakat menanggapi baik tentang produk yang dihasilkan, sehingga diperoleh penelitian akhir 97\% mengatakan bahwa video ini menarik perhatian mereka dan layak menjadi Media Promosi objek Wisata Ranu di Kabupaten Probolinggo.
\end{abstract}

Kata kunci: Video, media promosi, objek wisata, wisata ranu, Kabupaten Probolinggo, Jawa Timur.

\begin{abstract}
The rapid advances in information technology (IT) provide ease in accessing and presenting information in various forms and media, in general (books, brochures, magazines, tabloids and posters), as well as in electronic or digital format (internet, film, cd-interactive And games). With the availability of many presentations the results of research data can be presented with more interesting and easy to use then the results data is used, such as contains elements of information This media is a promotion video about Ranu Tourism in object Probolinggo District-East Java. The video provides info on Ranu tourism in Probolinggo District-East Java. This promotional media will be presented in the form of promotion videos and information that will make it easier for tourists to know about WIsata Ranu in Probolinggo-East Java regency it aims to captivate the attractiveness of the tourists both local and foreign tourists to come and know the have tour Probolinggo. MPEG (MotionPicture Expert Group) was chosen because it has several adventages, Including MPEG is an international standard for digital audio and video format, typically used for VCD and DVD. In creating a video as an attractive media campaign, the media is created with elements such as videography, storyline, storyboard, and audio concepts. Software support in the post-production stage is Adobe After Effect to create an opening, Adobe Photoshop to design information, and Adobe Premiere Pro is used for video editing process. From the results of the respondents, the percentage value of the community responded well to the resulting product, so that the final study of $97 \%$ said that this video attracted their attention and deserved to be the Promotion Media Ranu Tourism object in Probolinggo District.
\end{abstract}

Keywords: Video, promotional media, tourist attraction, ranu tour, Probolinggo District, East Java 


\section{PENDAHULUAN}

Probolinggo salah satu kabupaten di Jawa Timur yang menyimpan banyak wisata didalamnya. Probolinggo memiliki luas wilayah sekitar $1.696 .166 \mathrm{Km}$. Kondisi geografis wilayah, yang tepatnya terletak pada $112^{\circ} 51^{\prime}-113^{\circ} 30^{\prime}$ Bujur Timur dan $7^{\circ} 40^{\prime}-8^{\circ} 10^{\prime}$ Lintang Selatan serta berada pada ketinggian 0-2.500 m diatas permukaan laut. Probolinggo merupakan salah satu pilihan yang cocok bagi para wisatawan atau para pecinta alam untuk mengunjungi tempat ini dan melihat keindahan alamnya. Banyak tempat wisata di Probolinggo, mulai dari gunung, air terjun, ranu (danau), pantai, hutan mangrove, candi dan lain lain.

Probolinggo memiliki beberapa Ranu diantaranya Ranu Agung, Ranu Pada masa sekarang ini teknologi hampir menjadi kebutuhan yang sanga Segaran, Ranu Ronggojalu, dan lain sebagainya, Ranu berasal dari bahasa Jawa yang artinya danau atau kolam. Warga Probolinggo masih belum banyak yang mengetahui letak dari beberapa Ranu tersebut, karena tempatnya berada di pelosok desa yang jarang dilewati oleh kendaraan umum. Wisata Ranu di Probolinggo masih minim media promosi. Media promosi yang saat ini digunakan hanyalah baliho yang dipasang dipinggiran jalan, yang dirasa kurang efektif dan efisien. Belum ada media promosi visual seperti video yang mempromosikan Wisata Ranu di Probolinggo, sehingga tidak banyak warga Probolinggo yang tahu jika di Kabupaten Probolinggo terdapat Ranu yang luar biasa keindahan nya.

Pada umumnya bagi dunia pariwisata promosi sangat dibutuhkan sebagai media promosi, sehingga segaran mempublikasikan tempat wisata tersebut. Promosi yang baik adalah promosi yang bisa mempengaruhi sasaran sehingga memberikan dampak positif untuk perusahaan atau organisasi tersebut. Dalam pembuatannya, media promosi harus bersifat memberi tahu, mengajak, dan mempengaruhi. Yang terpenting media promosi harus bersifat informatif.

Maka berdasarkan uraian di atas penulis mengambil judul "Perancangan Video Promosi Objek Wisata Ranu di Kabupaten Probolinggo-Jawa Timur" Dan di harapkan video promosi ini dapat memberikan informasi dan mempengaruhi masyarakat lokal mau pun mancanegara untuk berkunjung di wisata Kabupaten Probolinggo.

Berdasarkan latar belakang diatas, maka penulis merumuskan masalah yaitu "Bagaimana merancang video promosi objek wisata Ranu Probolinggo-Jawa Timur yang efektif dan menarik?"

Agar pembahasan pang dari apa yang dirumuskan, maka diperlukan batasan batasan ini sebagai berikut : Objek penelitian di Probolinggo meliputi Ranu Agung, Ranu Segaran dan Ranu Ronggojalu, Software utama untuk mengedit video ini adalah adobe premiere cs3, software pendukung nya adalah adobe photoshop cs3 dan adobe after effect cs3.

Tujuan dari penulisan adalah untuk merancang sebuah video yang dapat digunakan sebagai media promosi wisata yang terdapat di Kabupaten Probolinggo. Dengan demikian Kabupaten Probolinggo dapat dikenal dengan berbagai wisata didalamnya, sehingga diharapkan dapat menarik minat para wisatawan domestik maupun mancanegara untuk berkunjung. Tidak hanya itu video ini dapat digunakan sebagai jembatan kerja sama antara 
pemerintah Kabupaten Probolinggo dan pemerintah kota yang ada di Jawa Timuruntuk mempromosikan tempat wisata.

Metode penelitian ini dilakukan melalui 3 (tiga) cara yaitu : Library Research (Riset Keperpustakaan)Metode penelitian yang berdasarkan keperpustakaan yang dijadikan dasar atau kerangka teoritis untuk penelitian dilapangan. Riset keperpustakaan dilakukan dengan cara pencarian referensi-referensi yang berhubungan dengan perancangan video promosi. Field Research (Riset Lapangan) Riset lapangan ini dilaksanakan dengan mengadakan observasi/survei langsung dilapangan yaitu pada objek penelitian wisata Ranu di Kabupaten Probolinggo. Dokumentasi Pemotretan dan pengambilan gambar sebagai bahan yang digunakan untuk membuat video promosi.

\section{PEMBAHASAN}

\section{Konsep Video}

Video Promosi ini untuk memberikan informasi tentang wisata Ranu di Kabupaten Probolinggo. Kabupaten Probolinggo yang terkenal dengan Gunung Bromo ternyata menyimpan banyak wisata alam salah satunya adalah Ranu (danau). Terdapat banyak ranu di kabupaten Probolinggo diantaranya adalah Ranu agung, Ranu segaran, Ranu Rongg jalu dan lain sebagainya. Video ini berisi keindahan dari Ranu agung, Ranu segaran dan Ranu Ronggojalu.

Kesan yang diangkat dalam video ini adalah simpel dan menarik. Simpel dari segi komposisi video yang ditampilkan berurutan dari suasana alam Kabupaten Probolinggo yang asri dilanjutkan objek wisata meliputi Ranu Agung, Ranu Segaran, Ranu Ronggojalu. Teknik pengambilan gambar dibuat berbeda-beda dalam setiap scene dengan mengkombinasikan type of shot, camera angle, dan pergerakan kamera agar video tidak terlihat monoton.Video promosi ini akan ditambahkan teks untuk informasi lokasi, audio berupa backsound.

Rangkaian Konsep ini dibuat untuk menampilkan keindahan, keasrian dan potensi dari beberapa objek wisata Ranu yang diambil. Konsep ini dibuat supaya wisatawan domestik maupun mancanegara berminat untuk berkunjung ke wisata yang ada di Kabupaten Probolinggo.

\section{Konsep Audio Visual}

Audio yang digunakan dalam video profil ini adalah audio instrument yang memiliki energi positif yang kuat untuk membangkitkan semangat pendengar. Musik instrumen ini sangat cocok untuk video promosi wisata.

Pemilihan font harus tepat serta tingkat keterbacaan yang mudah agar pesan yang ingin disampaikan bisa tepat sasaran dan mudah untuk diingat. Penggunaan font akan mempengaruhi kesan yang akan disampaikan dan juga berpengaruh pada target audience yang akan dicapai. Disini digunakan satu jenis font yaitu sans-serif. Font yang digunakan adalah lmpact dan tahoma. Font Impact digunakan untuk opening sedangkan font tahoma digunakan untuk memberikan informasi lokasi dari setiap objek wisata yang ditampilkan. Fontjenis sans-serif ini memberikan kesan informal, modern, efisien dan simple. 
Warna merupakan unsur desain yang pertama paling menarik perhatian seseorang dalam kondisi apapun. Dalam video ini menggunakan warna hijau dan biru. Warna-warna ini diambil karena mendukung sekali untuk menyampaikan pesan visual karena hijau mewakili alam dan biru melambangkan air.

\section{Storyline}

Penulisan Storyline ini dibuat mulai dari awal masuk di Kabupaten Probolinggo, masuk ke wisata Ranu Agung, Ranu Segaran dan Ranu Ronggojalu. Walaupun pada akhirnya saat produksi kemungkinan akan terjadi perubahan dalam pengambilan video. Berikut gambaran tabel dari storyline Video Promosi Wisata Ranu yang akan dibuat di Kabupaten Probolinggo.

Tabel 1. Storyline Video Promosi

\begin{tabular}{|c|c|c|c|}
\hline No & Sequence & Scene & Durasi \\
\hline 1 & Opening & 1. Pembukaan video & 5 Detik \\
\hline \multirow{3}{*}{2} & \multirow{3}{*}{ Di sawah } & 2. Matahari terbit & 3 Detik \\
\hline & & 3. Petani mencangkul sawah & 3 Detik \\
\hline & & 4. Seorang bapak mengayuh sepeda & 3 Detik \\
\hline \multirow{2}{*}{3} & \multirow{2}{*}{ Di jalan } & $\begin{array}{l}\text { 5. Gapura dengan tulisan Selamat } \\
\text { Datang dikabupaten Probolinggo }\end{array}$ & 5 Detik \\
\hline & & $\begin{array}{l}\text { 6. Memperlihatkan tulisan } \\
\text { Kabupaten Probolinggo }\end{array}$ & 3 Detik \\
\hline \multirow{8}{*}{4.} & \multirow{8}{*}{ Ranu Agung } & $\begin{array}{l}\text { 7. Memperlihatkan Jalan pedesaan saat } \\
\text { menuju Ranu Agung }\end{array}$ & 4 Detik \\
\hline & & $\begin{array}{l}\text { 8. Memperlihatkan petunjuk arah menuju } \\
\text { Desa Tiris }\end{array}$ & 3 Detik \\
\hline & & $\begin{array}{l}\text { 9. Petunjuk arah menuju Ranu Agung dan } \\
\text { Ranu Segaran }\end{array}$ & 5 Detik \\
\hline & & $\begin{array}{l}\text { 10. Memperlihatkan tulisan Wisata } \\
\text { Agropolitan di pinggir jalan menuju } \\
\text { Ranu Agung }\end{array}$ & 4 Detik \\
\hline & & 11. Tampak Ranu Agung dari atas & 3 Detik \\
\hline & & 12. Jalan setapak menuju Ranu Agung & 3 Detik \\
\hline & & $\begin{array}{l}\text { 13. Memperlihatkan mata air yang keluar } \\
\text { dari sebilah bambu }\end{array}$ & 3 Detik \\
\hline & & 14. Memperlihatkan aliran air di bebatuan & 3 Detik \\
\hline
\end{tabular}




\begin{tabular}{|c|c|c|c|}
\hline & & $\begin{array}{l}\text { 15. Memperlihatkan jalan setapak } \\
\text { menurun }\end{array}$ & 5 Detik \\
\hline & & $\begin{array}{l}\text { 16. Memperlihatkan Ranu Agung dari } \\
\text { depan dengan sampan yang terbuat dari } \\
\text { bambu. }\end{array}$ & 5 Detik \\
\hline & & $\begin{array}{l}\text { 17. Pemandangan air di ranu agung dan } \\
\text { alam hijau nya }\end{array}$ & 4 Detik \\
\hline & & $\begin{array}{l}\text { 18. Memperlihatkan pemandangan Ranu } \\
\text { Agung dari sisi kanan dengan perahu } \\
\text { bambu yang sedang berjajar rapi. }\end{array}$ & 3 Detik \\
\hline & & $\begin{array}{l}\text { 19. Pemandangan Ranu dari sisi kiri lagi } \\
\text { tapi dengan pemandangan yang } \\
\text { berbeda }\end{array}$ & 3 Detik \\
\hline & & 20. Pengunjung naik perahu di Ranu Agung & 4 Detik \\
\hline & & 21. Pemandangan Ranu dari depan & 4Detik \\
\hline & & $\begin{array}{l}\text { 22. Memperlihatkan Tebing Ranu Agung } \\
\text { dari sisi kanan }\end{array}$ & 5 Detik \\
\hline & & $\begin{array}{l}\text { 23. Pemandangan Tebing Ranu Agung dari } \\
\text { sisi depan }\end{array}$ & 3 Detik \\
\hline & & 24. Pemandangan Tebing dari sisi Kiri & 5 Detik \\
\hline & & $\begin{array}{l}\text { 25. Memperlihatkan air dan tebing Ranu } \\
\text { Agung dari sisi kiri }\end{array}$ & \\
\hline & & $\begin{array}{l}\text { 26. Memperlihatkan air dan tebing Ranu } \\
\text { Agung dari sisi kiri tapi dengan arah yang } \\
\text { berbeda }\end{array}$ & 3 Detik \\
\hline & & 27. Pemandangan Ranu Agung keseluruhan & 5 Detik \\
\hline 5 & Ranu Segaran & $\begin{array}{l}\text { 28. Memperlihatkan perjalanan menuju } \\
\text { ranu segaran }\end{array}$ & 3 Detik \\
\hline & & $\begin{array}{l}\text { 29. Memperlihatkan pemandangan } \\
\text { menuju Ranu Segaran }\end{array}$ & 3 Detik \\
\hline & & 30. Gapura masuk desa Segaran & 3 Detik \\
\hline & & 31. Pemandangan di Ranu Segaran & 3 Detik \\
\hline & & $\begin{array}{l}\text { 32. Pemandangan di ranu } \\
\text { segaran dari arah yang berbeda }\end{array}$ & 5 Detik \\
\hline & & $\begin{array}{l}\text { 33. Pemandangan ranu segaran dari arah } \\
\text { kiri dengan } \\
\text { memperlihatkan pengunjung }\end{array}$ & 3 Detik \\
\hline
\end{tabular}




\begin{tabular}{|c|c|c|c|}
\hline & & \multirow{2}{*}{$\begin{array}{l}\text { 34. Pemandangan Ranu Segaran dari } \\
\text { sisi kanan dengan memperlihatkan } \\
\text { sampan bambu } \\
\text { 35.Pemandangan Ranu segaran dari } \\
\text { depan dimana di depan Ranu ada gubuk } \\
\text { untuk berfoto selfie }\end{array}$} & \multirow{2}{*}{$\begin{array}{l}4 \text { Detik } \\
5 \text { Detik }\end{array}$} \\
\hline & & & \\
\hline & & $\begin{array}{l}\text { 36. Pengunjung yang sedang naik motor } \\
\text { boat di ranu Segaran }\end{array}$ & 3 Detik \\
\hline & & $\begin{array}{l}\text { 37. Para pengunjung yang sedang berfoto } \\
\text { ranu Segaran }\end{array}$ & 3 Detik \\
\hline & & $\begin{array}{l}\text { 38. Pemandangan Hutan pinus di ranu } \\
\text { segaran }\end{array}$ & 5 Detik \\
\hline & & $\begin{array}{l}\text { 39. Pengunjung yang sedang berjalan } \\
\text { menuju hutan pinus }\end{array}$ & 3 Detik \\
\hline & & $\begin{array}{l}\text { 40. Pemandangan Hutan pinus dan Ranu } \\
\text { segaran }\end{array}$ & 5 Detik \\
\hline \multirow[t]{10}{*}{6} & \multirow[t]{10}{*}{ Ranu Ronggojalu } & 41. Jalan menuju Ranu Ronggojalu & 3 Detik \\
\hline & & $\begin{array}{l}\text { 42. Pemandangan selama perjalanan ke } \\
\text { ranu Ronggoojalu }\end{array}$ & 4 Detik \\
\hline & & 43. Pemandangan di ranu Ronggojalu & 3 Detik \\
\hline & & $\begin{array}{l}\text { 44. Memperlihatkan birunya air di ranu } \\
\text { Ronggojalu }\end{array}$ & 4 Detik \\
\hline & & $\begin{array}{l}\text { 45. Memperlihatkan ikan ikan kecil yang } \\
\text { berenang di ranu Ronggojalu }\end{array}$ & 4 Detik \\
\hline & & $\begin{array}{l}\text { 46. Memperlihatkan sekumpulan anak kecil } \\
\text { yang mandi di ranu Ronggojalu }\end{array}$ & 4 Detik \\
\hline & & $\begin{array}{l}\text { 47. Memperlihatkan sekumpulan anak kecil } \\
\text { melompat dari bagian jembatan ranu } \\
\text { Ronggojalu }\end{array}$ & 3 Detik \\
\hline & & $\begin{array}{l}\text { 48. Memperlihatkan keindahan di ranu } \\
\text { ronggo jalu dari sisi timur }\end{array}$ & 3 Detik \\
\hline & & $\begin{array}{l}\text { 49. Memperlihatkan keindahan ranu ronggo } \\
\text { jalu dari sisi utara }\end{array}$ & 3 Detik \\
\hline & & $\begin{array}{l}\text { 50. Memperlihatkan jembatan di ranu } \\
\text { ronggojalu }\end{array}$ & 3 Detik \\
\hline 7 & Penutup & 51. Ucapan Terimakasih & 10 Detik \\
\hline
\end{tabular}




\section{Story Board}

Sebelum melakukan proses pengambilan video penulis akan membuat sebuat perancangan yaitu stroyboard. Storyboard disini suatu hal yang sangat membantu dalam tahap produksi yang bertujuan sebagai dasar data panduan dalam pengambilan video agar tidak terjadi pengulangan dalam pengambilan video. Walaupun pada akhirnya saat produksi kemungkinan akan terjadi perubahan dalam pengambilan video. Berikut gambaran tabel dari storyboard video promosi yang akan dibuat.

Tabel 2. Story Board

\begin{tabular}{|c|c|c|c|}
\hline No & Gambar & Keterangan & Durasi \\
\hline 1 & Opening & Judul Video & 3 Detik \\
\hline 2 & & $\begin{array}{l}\text { Memperlihatkan } \\
\text { matahari terbit di } \\
\text { perswahan } \\
\text { Type Shot : Long Shot (LS) }\end{array}$ & 3 detik \\
\hline 3 & & $\begin{array}{l}\text { Seorang petani sedang } \\
\text { mencangkul sawah } \\
\text { Type Shot : Long Shot (LS) }\end{array}$ & 3 detik \\
\hline 4 & & $\begin{array}{l}\text { Seorang petani mengayuh } \\
\text { sepedanya menyusuri sawah } \\
\text { Type Shot : MS }\end{array}$ & 3 detik \\
\hline 5 & & $\begin{array}{l}\text { Di Jalan dengan tulisan Selamat } \\
\text { datang dikabupaten } \\
\text { Probolinggo } \\
\text { Type shot : ELS }\end{array}$ & 5 detik \\
\hline 6 & & $\begin{array}{l}\text { Memperlihatkan } \\
\text { Kabupaten Probolinggo Typan } \\
\text { Shot (LS) }\end{array}$ & 4 Detik \\
\hline
\end{tabular}




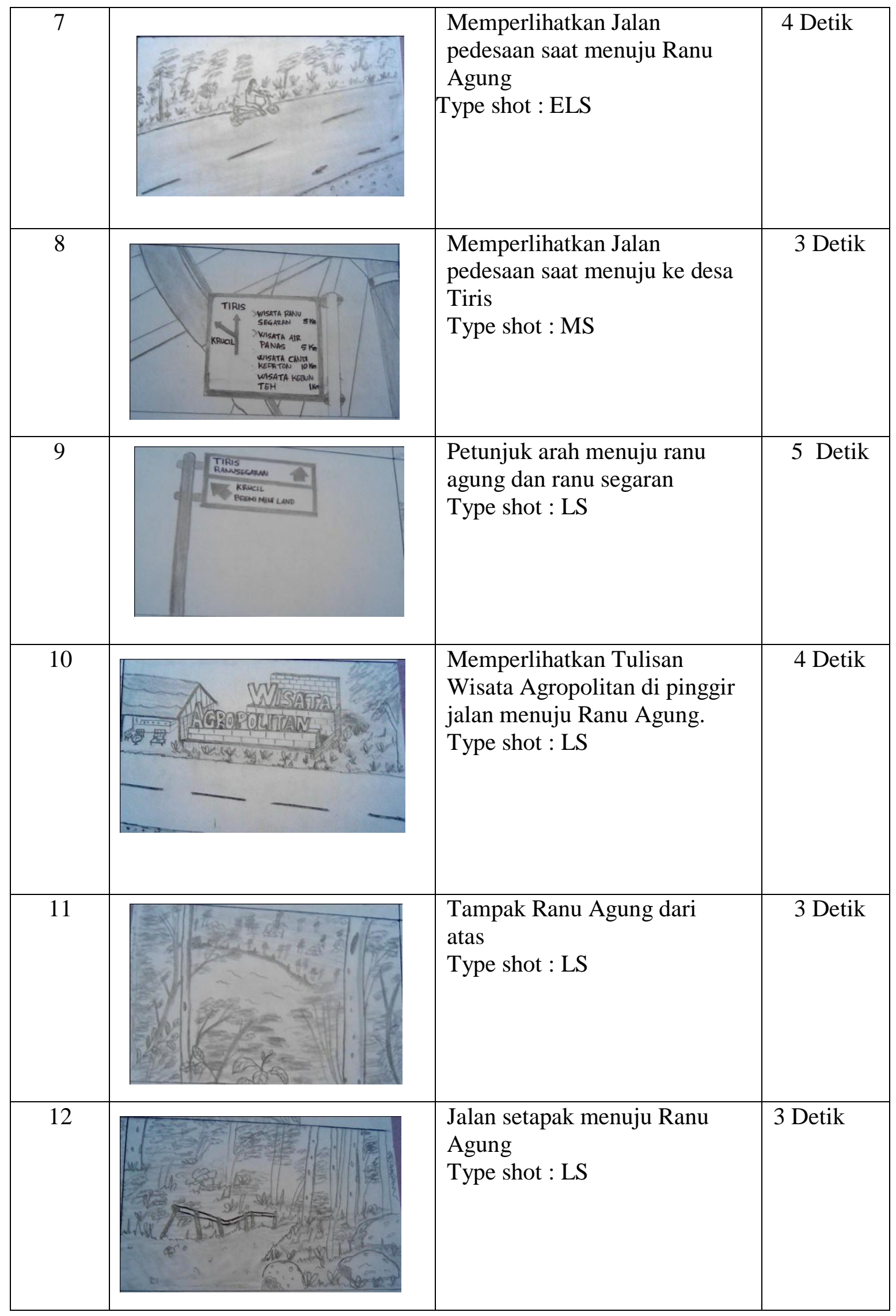




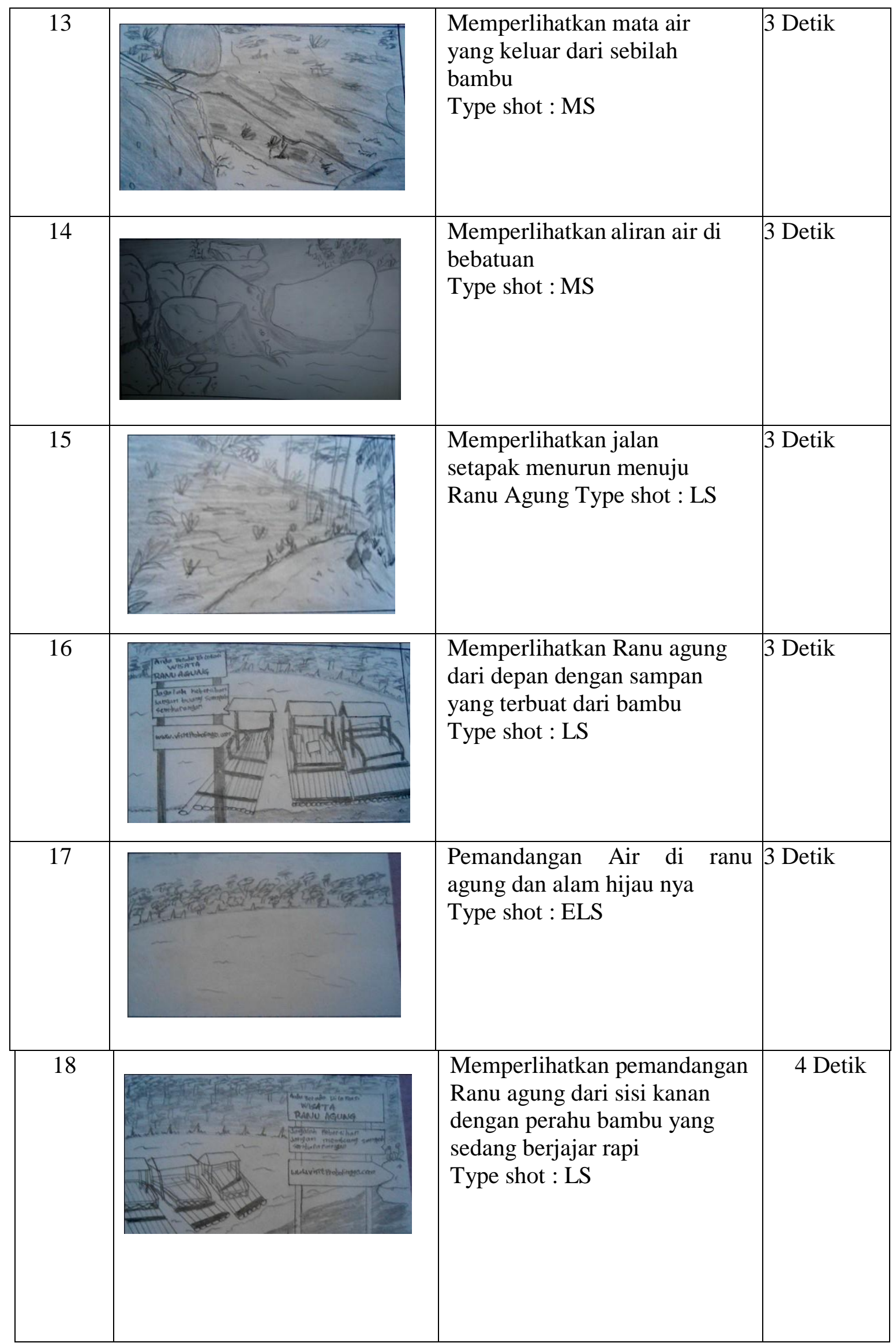




\begin{tabular}{|c|c|c|c|}
\hline 19 & 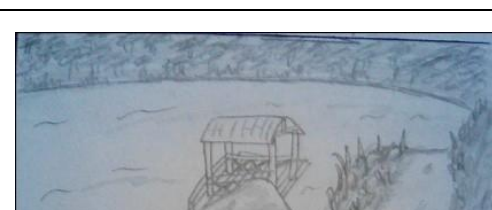 & $\begin{array}{l}\text { Pemandangan Ranu dari sisi } \\
\text { kiri lagi tapi dengan } \\
\text { pemandangan yang berbeda } \\
\text { Type shot : ELS }\end{array}$ & 4 Detik \\
\hline 20 & & $\begin{array}{l}\text { Pengunjung naik perahu di } \\
\text { ranu agung Type shot : ELS }\end{array}$ & 5 detik \\
\hline 21 & & $\begin{array}{l}\text { Pemandangan Ranu dari } \\
\text { depan } \\
\text { Type shot : ELS }\end{array}$ & 3 detik \\
\hline 22 & & $\begin{array}{l}\text { memperlihatkan Tebing } \\
\text { Ranu Agung dari sisi kanan } \\
\text { Type shot : ELS }\end{array}$ & 3 detik \\
\hline 23 & & $\begin{array}{l}\text { Pemandangan Tebing } \\
\text { ranu Agung dari sisi } \\
\text { depan Type shot : ELS }\end{array}$ & 4 detik \\
\hline 24 & & $\begin{array}{l}\text { Pemandangan Tebing } \\
\text { dari sisi Kiri Type shot : } \\
\text { ELS }\end{array}$ & 4 detik \\
\hline
\end{tabular}




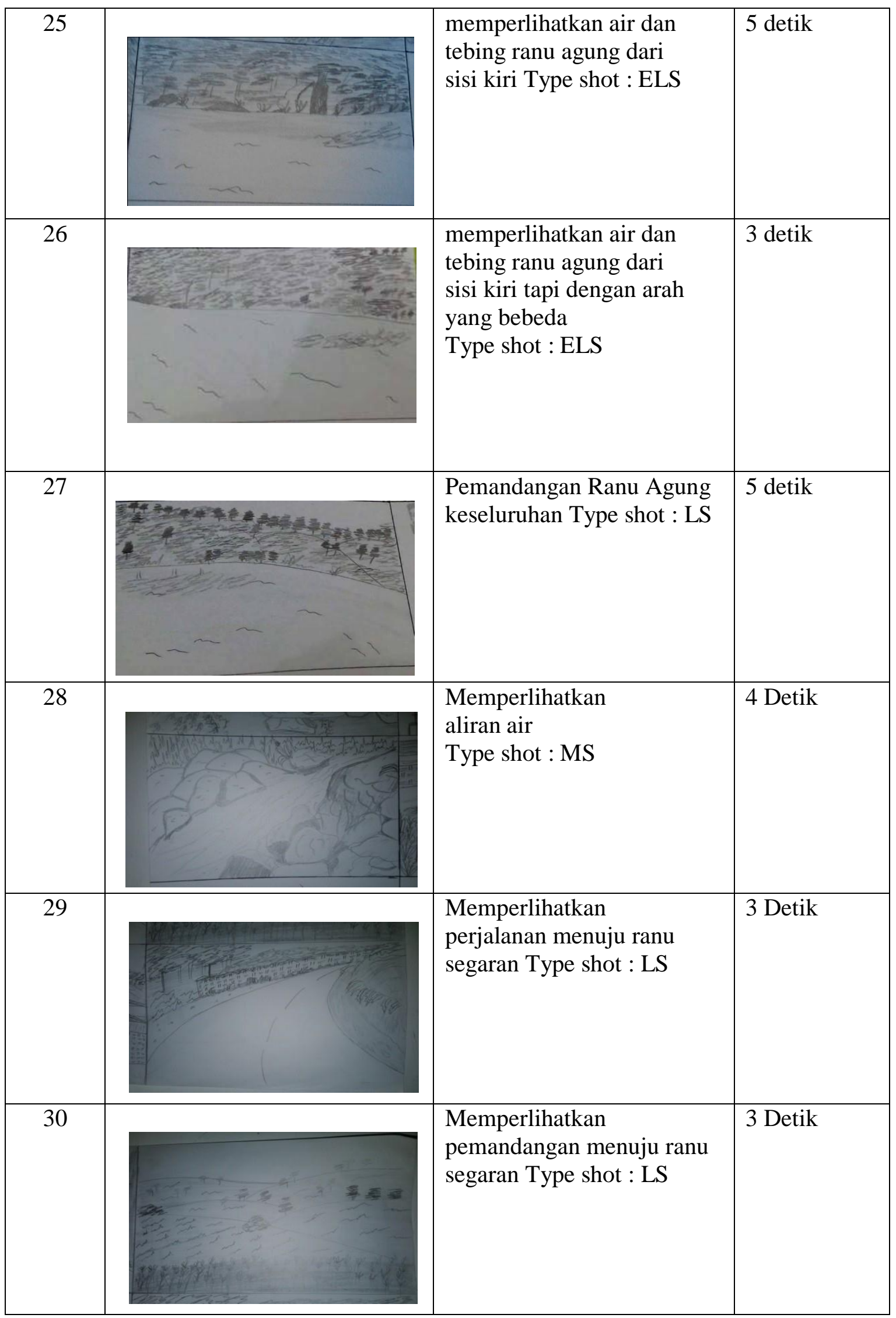




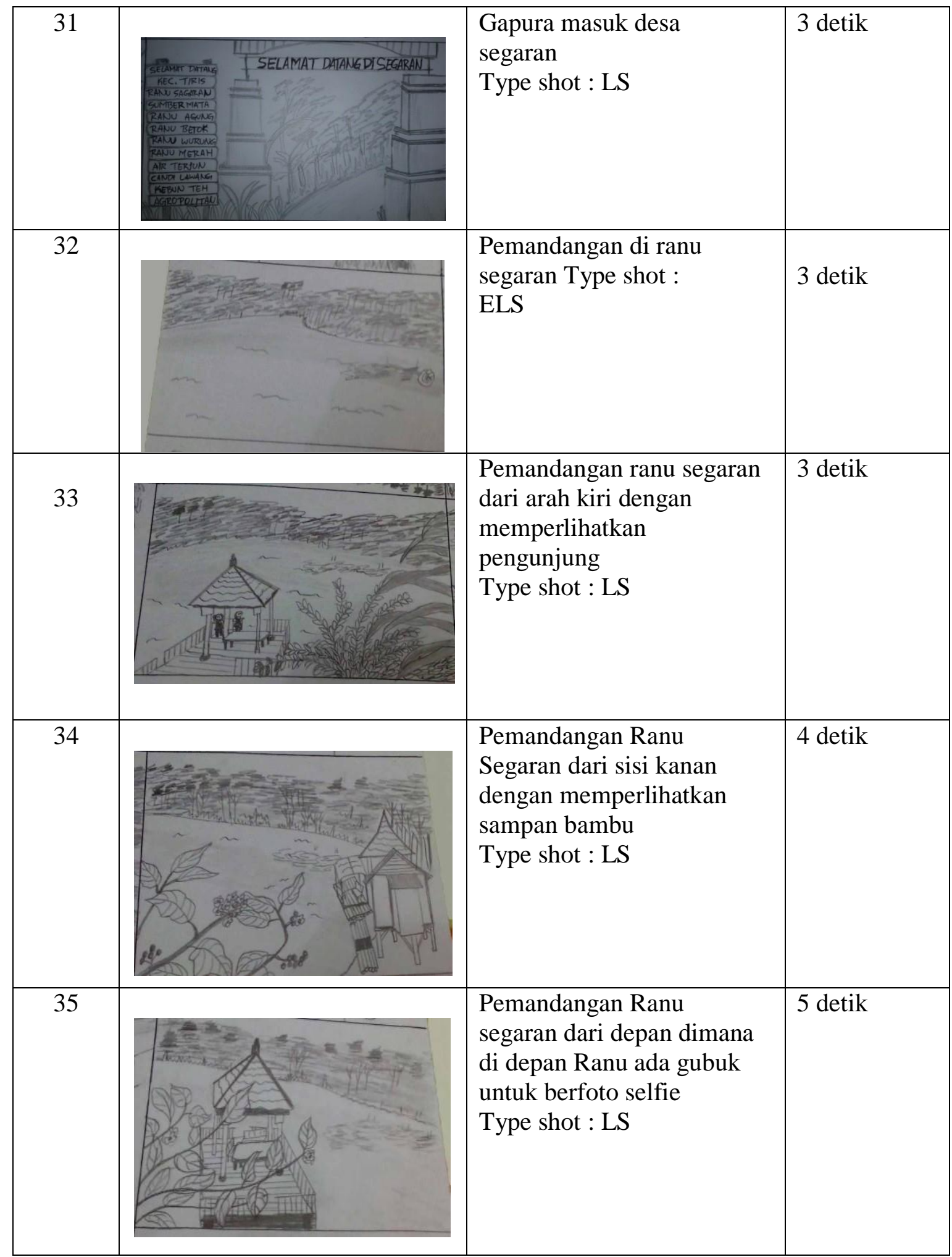




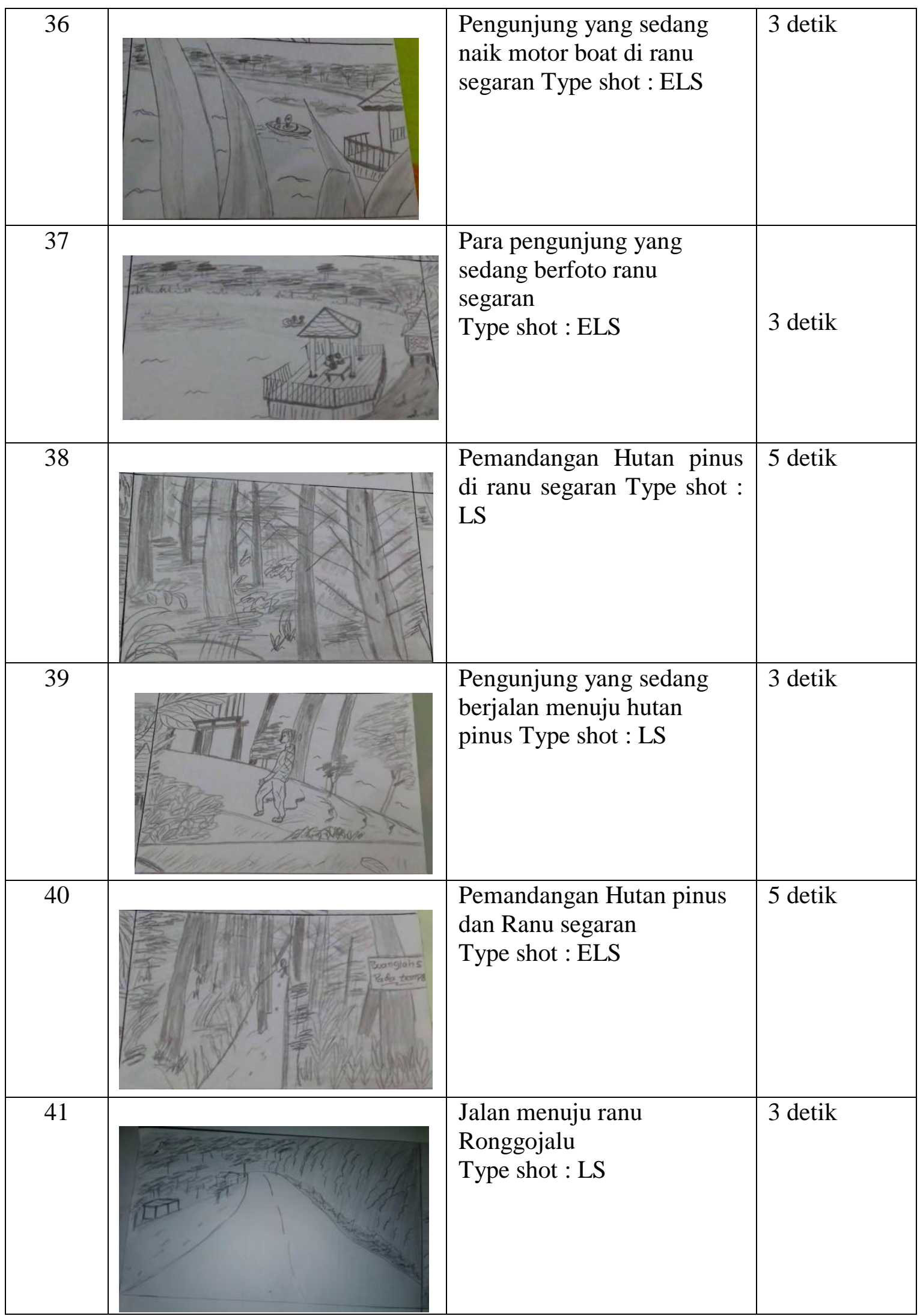




\begin{tabular}{|c|c|c|}
\hline 42 & $\begin{array}{l}\text { Pemandangan selama } \\
\text { perjalanan ke ranu ronggoo } \\
\text { jalu Type shot : LS }\end{array}$ & 4 detik \\
\hline 43 & $\begin{array}{l}\text { mandangan di } \text { Ranu } \\
\text { onggojalu Type shot : } \\
\text { S }\end{array}$ & 3 Detik \\
\hline 44 & $\begin{array}{l}\text { emperlihatkan birunya air } \\
\text { ranu ronggo jalu } \\
\text { pe shot : LS }\end{array}$ & 4 detik \\
\hline 45 & $\begin{array}{l}\text { emperlihatkan ikan ikan } \\
\text { cil yang berenang di ranu } \\
\text { gggo jalu } \\
\text { pe shot : MS }\end{array}$ & 4 Detik \\
\hline 46 & $\begin{array}{l}\text { emperlihatkan sekumpulan } \\
\text { ak kecil yang mandi di } \\
\text { uu ronggo jalu } \\
\text { pe shot : MS }\end{array}$ & 4 Detik \\
\hline 47 & $\begin{array}{l}\text { emperlihatkan sekumpulan } \\
\text { ak kecil melompat dari bagian } \\
\text { nbatan ranu } \\
\text { pe shot : LS }\end{array}$ & 3 detik \\
\hline
\end{tabular}




\begin{tabular}{|c|c|}
\hline 48 & 3 Detik \\
\hline 49 & 3 detik \\
\hline 50 & 3 detik \\
\hline 51 & 10 Detik \\
\hline
\end{tabular}

\section{KESIMPULAN}

Berdasarkan pemaparan pada bab-bab sebelumnya dan berdasarkan pengujian melalui kuisioner maka dapat diambil kesimpulan bahwa perancangan video promosi ini mengenalkan tiga tempat objek wisata ranu yang ada di Kabupaten Probolinggo. Dalam perancangan video promosi ini, tempat, penerapan teknik pengambilan gambar serta audio yang sesuai dengan target audience dapat membuat video ini menarik untuk dilihat. Melalui hasil kuisioner $100 \%$ dari 30 responden tertarik untuk berkunjung ke wisata di Kabupaten Probolinggo.

\section{DAFTAR PUSTAKA}

Albertus Agastya M. Pengaruh Desain Produk Terhadap Keputusan Pembelian Produk Sepatu Futsal Specs di Kota Bandung.

Kotler, Phillip dan Gary Amstrong. 2001. Prinsip-Prinsip Pemasaran. Jakarta: Penerbit Erlangga.

Kotler, Philip \& Keller, Kevin Lane. 2009. Manajemen Pemasaran. Jakarta: Erlangga

Made Laksmi Saraswati1, Ari Pradhanawati, Wahyu Hidayat. Pengaruh Desain Produk, Kualitas Produk, dan Harga Terhadap Keputusan Pembelian Pada Kampung Batik Wiradesa, Kabupaten Pekalongan. 
Mahmud, Eko Agus Alfianto. Pengaruh Desain Produk Dan Layanan Purna Jual Terhadap Keputusan Konsumen Membeli Sepeda Motor Yamaha Merek NEW VIXION FI (Full Injection)

Padmantyo, Sri, Eko Purnomo. Pengaruh Desain Produk dan Promosi Terhadap Volume Penjualan Pada Industri Batik (Studi Pada Industri Batik di Kabupaten Sragen) 